\title{
CHANGING WORK, WORK PRACTICE: CONSEQUENCES FOR VOCATIONAL EDUCATION
}

\author{
Stephen Billett, Griffith University, Australia
}

\section{Changing work, changing workers}

This chapter discusses the changing and emerging characteristics of work, work practice and work requirements, and their consequences for vocational education. Changing patterns in work and working life are proposed as comprising: (i) the kind of available; (ii) how individuals participate in work; (iii) what constitutes competence within that work, and (iv) those participating in work. The consequences for vocational education are systemic in terms of the kinds of occupations that need to be developed, variations in and complexity of work requirements, shifts in employer-employee relations, and the demographic shifts in those who will need to be supported by vocational education. The chapter elaborates these patterns of change to work and working life and discusses policy and curriculum practice associated with each. Overall, it argues that, the changes to work make it more demanding, and the frequency of change in work and how work is practised, demands careful, comprehensive and targeted preparation and on-going development. Moreover, with broader participation in the work force and longer working lives, the arrangement for this preparation and ongoing development will need to be targeted, differentiated and sustained.

\section{Changes in the kinds of work available}

In the last quarter of the previous century and continuing into this, there have been considerable changes to the kinds of work available across and within countries (Handel 2005, McBrier \& Wilson 2004). Change in the demand for particular kinds of paid employment (occupations) are shaped by continuities and transformations in the requirements for vocational practice in the particular countries or regions. As these requirements are subject to constant change, the demand for particular occupations, transform both the quantum and kinds of the available paid work. Through this process, some occupations are reshaped, transform or simply disappear. This means that the availability, location and accessibility of particular kinds of paid work also change. Although the character and scope of these changes differ across countries and economies, there are some trends that are consistent across many countries with Western-style economies (e.g. United States, Britain, Australia, Canada).

These trends include a reduction in the demand for 'semiskilled' and 'unskilled work' and an increase in demand for professional, technical and administrative work, and also service work, yet much of it 'low skill' (Noon \& Blyton 1997). For instance, there has been considerable decline in the number of workers engaged directly in farm work, which impacts on farm workers and farming communities. In the United States, the decline 
in farming employment commenced in the early 1950s, and plateaued by the mid-1970s (Department of Labor 2005). So, the agricultural sector and agricultural communities experienced decline with only a fraction of the numbers of people employed in farm work in communities where it was previously available. However, this sector remains as a major source of employment. Because of the centralisation and intensification of US food production, many more workers are employed in the processing and distribution of farm products: 'from the gate to the plate'. This change indicates shift in forms of work required or available in this sector.

There has been significant decline in employment within manufacturing jobs in many western countries. Between 1940 and 2002 the American manufacturing labour force declined from $48 \%$ to $28 \%$ of the workforce (Employment Policy Foundation, 2003), in Australia between 1983 and 1999 it declined from 18.1\% to 12.8\% (Pusey 2003). Like agriculture, the impact of this decline impacts both individuals who work in those sectors and the communities in which they live. While some of this decline is a result of laboursaving technologies and manufacturing work being exported to other countries. So, while manufacturing work in countries such as Australia, United Kingdom and United States, has declined it has grown significantly as a portion of the Korean labour work force and now constitutes the single largest category of employment at 32\% (Korean Economic Planning Board 2005). Then, there is the centralisation of specialised manufacturing (e.g. aircraft, automotive, shipbuilding) which sees particular forms of high and specifically skilled employment restricted to particular locations and countries.

So, in different ways, the transformation of economic activity through increased use of technology, the export of jobs to other countries and emerging community needs is having a profound effect on the availability of particular kinds of work. Yet, claims of a general trend towards high skill work is contradicted by a burgeoning service industry sector in some countries such as the United States, Britain and Australia where this kind of work is often characterised as being low paid and low skill (Carnoy 1999). In these countries, there is also some growth in the allied health and community work sectors (e.g. community health and aged care) that are emerging as responses to changing demographics. Yet again, much of this work is characterised as low paid and low skill.

With the growth in employment being largely within professional, technical and service work, there is a hollowing out of mid-skill work and the polarising between high and low skill workers. These patterns of growth, like those of manufacturing and agriculture, are largely unidirectional indicating structural changes in the work available. For instance, in 1940, American managers and professionals were only $18 \%$ of the non-farm labour force, yet by 2002 they comprised 32\% of the labour force (Employment Policy Foundation, 2003). Barley and Orr (1997) claim that the number of professional and technical jobs in America have increased over $300 \%$ since 1950, overshadowing increases in sales work (248\%) and managerial work (182\%). Yet, other shifts in the labour market complicate this trend. During the 1980s, there were significant 
declines in mid-level managerial positions in the United States. At a time when many African-Americans were gaining middle management jobs, they are claimed to have experienced declines in their careers more frequently and severely than their white counterparts (McBrier \& Wilson 2004). This suggests another dimension of the hollowing out thesis, based on factors other than human capital.

The reduction of manufacturing employment in Australia has been overshadowed by the decline in public sector employment (31\% to $20 \%$ ), which was matched by a comparable increase in private sector employment (Pusey 2003). Although reflecting the trend of strong employment in professional and managerial work, the shift from public sector to private sector employment for such large numbers of Australian workers would include significant impacts upon their work, careers and working lives. So even within employment categories that are experiencing overall growth, there can be quite different outcomes for groups of workers. Barley and Orr (1997) claim that many jobs have been so transformed that the existing occupational categories no longer reflect the division within contemporary workforces. For instance, transformations in the printing industry has seen technological innovations cause a wholesale transformation in the skills required as hot metal printing processes were replaced by information-processing and printing technologies. Clearly, as work requirements change, quite different skill sets are required to secure and maintain employment in these sectors.

So, significant patterns of change are occurring in the kinds of work available in particular countries, localities and in what constitute categories and kinds of occupations. There are long-term consequences for these occupations, and those wishing to maintain secure employment in particular kinds of occupations and for communities. The implications include capacities to form and sustain a career throughout working lives, and the prospect of dealing with shifts in locations, wholesale transformation in work requirements and even the demise of particular occupations. For vocational education, it means that beyond initial preparation there has to be curriculum and certification arrangements that can assist occupational transitions throughout individuals' working lives.

\section{Changes in participation in work}

How individuals engage in work and the organisation of that work is being transformed, and in diverse ways. This has implications for the capacities individuals require and how their skill development is secured throughout their working lives. There are shifts to increasingly 'non-standard' forms of employment practices. These can comprise contingent forms of employment (e.g. part-time, contract based and non-continuing) that, in the main, are involuntary (Lipsig-Mumme 1996). Across many Western-style economies, the number of workers who are employed in these kinds of work arrangements is high and increasing. In Australia, Pusey (2003) notes that full-time employment declined between 1985 and 2000 from 82\% to $74 \%$ of the workforce. In Britain, the percentage of employees working part-time increased from 21\% in 1991 to 27\% in 2000 (UK Labour Force 
Survey). Similarly, temporary jobs increased from $4 \%$ to $8 \%$ and selfemployment rose from $7 \%$ to $11.6 \%$. There are also other forms of nonstandard work that are reshaping the organisation and conduct of work, such as working from home, or otherwise being remote from the worksite. The advent of low-cost forms of information technology has provided employment circumstances in which workers are less required to be physically located in a particular workplace. Yet, as with contingent work, these workers refer to difficulties to maintain their contact with and understanding of what constitutes the requirements for work, particularly as these are subject to change (Noon \& Blyton 1997)

As with the changes to the kinds of occupations that are available, these non-standard forms of employment are deployed and experienced differently across workforces. Involuntary contingent work arrangements are less likely to be experienced by highly skilled or high-paid workers, but more likely to be the experience of lower paid and low skilled workers, such as those in the service sector (Bernhardt 1999). These employment arrangements are counter to orthodox labour market practices, as they are characteristic of times of high unemployment. Yet, in countries such as Australia, the United States and Britain, contingent work situations have continued even within times of high economic activity and performance. All this contradicts and stands in contrast to what was predicted for the contemporary workforce.

In the 1990s it was predicted that most work in western economies would become high skilled, increasingly self-managed and high discretionary (Carnevale 1995). Yet such arrangements have only been afforded to a minority of workers (Bernhardt, 1999, Berryman, 1993). Highly skilled professionals are most likely to experience such work arrangements, but they remain a remote prospect for service and retail workers. As Bernhard (1999) suggests some retail work is deliberately down-skilled to secure low levels of pay and maximise opportunities for using part-time and contingent workers. Technology, which is increasingly becoming a requirement of workplace performance, can be used to deskill these workers, including marginalising their discretion. For instance, massive technological investment by the retailer Wal-mart has been used to keep inventories responsive to turnover patterns. Here, some tasks are being transferred to suppliers who can re-supply stores based on access to records about product sales (Bernhardt 1999). Yet, these changes have been driven by technological and process innovation - not on the basis of making work more expansive and skilled. Although these are not 'high performance workplaces', their operations are highly profitable. Hence, it is unlikely that retailers like these will engage in expanding employees' work.

The prospects for expansive work practices are based upon perceptions of the complexity of work and the standing of workers. Darrah (1997) notes that in a company manufacturing computers that the system designers were seen to be the most high status and afforded greater levels of support and professional development. Yet, analysis of the work conducted by production workers indicated that their skill requirements 
were as least as demanding as those of the system designers. Nevertheless, the production workers were rarely given opportunities to develop their skills further nor were involved in organisational decision making, even that associated with production matters. So, perceptions about the standing of individuals' work can influence how workers participate in and contribute to the workplace. Moreover, the bases by which employers support employees in their ongoing development throughout their working life appears also to be marked by diversity. Studies from America and across Europe indicate the same trend. Employers are more likely to spend funds on and support younger, more educated, skilled and male workers who speak the native language than those who are older, less educated and skilled, female and who do not speak the native language (Brunello \& Medio 2001). They are most likely to support the kinds of workers who are best able to fend for themselves, probably because these workers are seen to be more valuable and less replaceable.

So consideration of expansive and high performance workers needs to include the broader requirements for being able to perform vocational practice in dynamic, intense and differentiated circumstances. This enunciates requirements for the development of workplace capacities that go beyond technical competence and emphasise how this technical knowledge might be applied, managed and used strategically in fluid and transforming work practices. Beyond the prospects of institutional support (e.g. workplaces, educational institutions) the agency of individuals as learner-workers will be central to their effective ongoing participation in work.

\section{Changes in the requirements for work}

It follows from the above that the requirements for work performance will change continuously throughout individuals' working lives. Regardless of whether work is up skilling or down skilling, the requirements for work are changing. This means individuals will need to actively maintain their workplace competence. These changing requirements will be manifested in particular ways across workplaces and will vary in terms of the breadth and scope of change. Yet, some requirements are likely to be comprise work that is more: (i) non-routine; (ii) specialised and diverse; (iii) intense; (iv) conceptual; (v) discretionary; (vi) complex; and (vii) based on interactions with others, tools and artefacts. Each of these has implications for vocational education.

Work is becoming less routine

Regardless of whether work is being up-skilled or down-skilled, it is increasingly subject to change and transformation. This makes it less routine, demanding continuos learning. Production and service cycles are getting shorter (Bailey 1993). Technology brings about changes as it moves through cycles of introduction, growth, stability and then further change (Bartel \& Lichtenberg 1987), with these cycles becoming increasingly shorter and overlapping. Consequently, workplace 
competence premised on engagement with technology can be fleeting. A car mechanic claimed each model of automobiles has particular nuances associated with its operations, maintenance and mechanical problems. Beyond general mechanical knowledge, familiarity with particular models of cars is central to mechanics' workplace competence developed over time in working on these vehicles (Billett \& Somerville 2004). However, the replacement of one model by the next, nullifies the value of existing nuanced knowledge. The mechanics must learn, through experience, the mechanical foibles of new models. In this way, the frequency of change that workers are subject to means the frequency they have to learn anew.

Some implications for vocational education are as follows. The degree by which the requirements for work are novel or new to the worker makes this learning an easier or more difficult task. Learning tasks that are similar to what has been experience before are easier to learn because of their existing knowledge to engage with and understand new requirements. Changing from one form of word processing package to another might be not too difficult. However, tasks that are novel to individual can represent a significant learning task, with the danger of overwhelming individuals' learning. Importantly, beyond the objective requirements of the tasks to be learnt, the degree the task is novel is person-dependent. That is, what will be a routine activity for one individual, maybe non-routine for another. Women returning to clerical work after being principal care-givers for their children are confronted by significant transformation in technological requirements of clerical work (e.g. using word processing, spreadsheets and electronic mail). For the worker whose previous competence was with a typewriter, there is a requirement for considerable skill development.

So the degree to which learning tasks are novel to individuals likely determines the level of support required to guide theirs developing and maintaining competence for effective work performance. Generally, new learning or the adaptation of existing knowledge is the kind of learning that most likely requires guidance by more expert others to assist and guide the learning process. This can include demonstrating practices, elaborating concepts and assisting individuals' access to knowledge they might not other wise be able to learn.

\section{Specialisation and diversification}

A need for specialisation or diversification or both arises as workplace change. Particular technologies require individuals to become specialised in their operation, because expensive equipment, or complex processes requires specific expertise. Conversely, and particularly in workplaces that have downsized -- reduced the number of workers -- the remaining workers are required to be multi-skilled to perform a wider range of tasks. Individuals might need to be more broadly skilled and engage in a wide range of activities that demand a broader range of work competencies. The motor mechanic referred to above, noted the way that longer vehicle warranties have changed motor mechanics' work. These warranties tend to wed car owners to the garage from which it was purchased and mechanics' jobs becomes concerned with maintaining close contact with and providing 
a service for a clients over a longer period (Billett \& Somerville 2004). Mechanics may have to develop skills associated with communication explanations and being patient with clients' complaints or request.

Therefore, depending on the degree by which individuals are asked to develop specific skills or to be more broadly skills suggests different but particular kinds of skills development. Both the scope and depth of work requirements demand particular kinds of vocational preparation: the broadening of the vocational base and the development of specialisms through richer procedural and conceptual knowledge of particular domains of activities.

Intensity of work

To provide high-quality goods and services, work is becoming more intense through the need to compete locally and globally. For instance, changes to medical practices have made nurses' work more intensive. Hospital wards once had patients recuperating requiring little intensive care by nurses, who could focus their attention on sick patients who needed their care. Now patients often recuperate elsewhere (e.g. home), leaving hospital wards to be full of sick patients all requiring the nurses' attention. This makes their work more intense. Managing intense work requires monitoring, prioritising and conducting multiple tasks simultaneously (Bertrand \& Noyelle 1988). This requires considering a range of factors, making and enacting decisions and monitoring execution of a number of tasks simultaneously. So, there are higher order capacities required to manage work that is intense, and these capacities have to be developed for effective work practice. Developing these kinds of capacities represents key goals for vocational education, yet are not likely to be easily developed through classroom based activities.

\section{Conceptual requirements}

Work requirements might also become more opaque -- difficult to comprehend and increasingly reliant upon conceptual and symbolic knowledge -- particularly where technology requirements are high. There have always been conceptual elements to working knowledge (e.g. force factors, process considerations). These are increasingly becoming a requirement for contemporary and emerging work practice. Technology often particularly requires understandings premised on conceptual and symbolic knowledge, than when individuals engage more directly with their work activities. Computer-controlled lathes, for instance, require levels of symbolic and conceptual knowledge that is distinct from those required for operating a manual lathe (Martin \& Scribner 1991). The former requires the operator utilises digital coordinates and commands, that are more abstract and may be more difficult to engage with and learn than those from physical engagement and observation (Zuboff 1988). Similarly, while bedside computers can ease nurses' workload through performing routine monitoring tasks (Cook-Gumperez \& Hanna 1997), this technology requires understanding operations and functions represented in digital forms, rather than those physically engaging with or 
through observing a patient. Further, the separation between the operator and the object upon which they are working makes the task of understanding more difficult (Zuboff 1988).

With increases in technology use, the requirements to work with forms of conceptual and symbolic knowledge are likely to become more common, and therefore a goal for vocational education. Because of the demands associated with the learning of conceptual and symbolic knowledge, it may be necessary to use specific instructional devices to secure understanding. Without specific instructional interventions this 'hard to learn' knowledge will not successfully learn this more opaque symbolic knowledge.

Enhanced discretionary and complexity in work Although the promise of high discretion work has not been realised universally, the discretionary qualities of many forms of work are increasing for many if not all workers. Job expansion (e.g. cross-skilling) and changes to workplace practices, such as the flattening of organisational structures often bring with it increased demands for workplace discretion (Noon \& Blyton 1997). These changes may require workers to make more decisions and take into account an increased array of work-related factors in their work, thereby making the requirements for effective work performance more complex. Complexity refers to the number of compounding factors that need to be considered or take into consideration when enacting a work task. From the examples above, work requirements are becoming more complex because of their novelty, job expansion or specialisation, the conceptual knowledge needing to be exercised, and the broad range of discretionary qualities needing to be exercised through work. For many, the demands for effective work performance are increasing. Ironically, this may not be the intention of workplace management, who may even wish to simplify and deskill work (Danford 1998). Yet, the range of factors which underpin much of contemporary and emerging work, including the constancy of the change, suggests that regardless of these intents that work itself is becoming increasingly demanding to maintain competence, because of the kinds of barriers that are erected to subordinate and control, around which workers have to work to exercise their sense of self as individuals and workers.

Workplace interactions

In addition to the changing characteristics of work tasks as outlined above, the requirements for workplace interactions with others and technologies are transforming and likely increasing. Across a range of occupations and kinds of work practice, there seems to be growing demands for individuals to work as teams, even if they are not interested in or empowered through these arrangements (Darrah 1997). Nevertheless, the distribution of activities across groups of workers and flatter organisational structures premised on a reduction in direct supervision (McGovern 1996) demand increases in workplace interactions. These include requirements for negotiation and working with others in order for work to be commonly 
understood, communicated and conducted. Such requirements are complicated by the breadth of work individuals engage in, the cohesiveness of teams and shared understandings about work (Billett, Smith \& Barker 2005). The ability to communicate, capacity to engage with others is emerging now as a basic requirement for work. Beyond being able to communicate orally and in written form, there are also work practices requirements that are both a product of and premised on workplace interactions. Moreover, and related to the requirements for developing the conceptual and symbolic capacities required for work, are the requirement to interact with tools and artefacts, technologies of different kinds is increasing as technologies are deployed to conduct work and communicate about it. So, together, the growing requirements for interactions with others, tools and technologies suggest that these aspects of work performance likely require particular capacities and, therefore, forms of development.

Overall, the requirements for contemporary and emerging work practices are more demanding than in the past. Yet, not all of these requirements are new. There have always been new activities, the specialisation and diversification, intense forms of work and conceptual underpinnings for effective work, discretionary qualities and capacities interact with others and artefacts. However, currently and, likely, in the future there will be a requirement for these capacities to be learnt with greater frequency and collectively will play out in ways that will make work more demanding and therefore requiring more thorough initial preparation and continuity in the future. It seems that initial vocational preparation will need to be thorough and go beyond just work techniques and provide for the ongoing development of vocational practice focussed and strategic.

\section{Changes in who is participating in work}

Having identified changes in the forms of work available, their conduct and performance requirements; there are also changes in those who are participating in work. That is, in those who require initial preparation and ongoing development throughout working life. The most significant increase in many Western countries is women's participation in the labour force. Between 1970 and 2000, the participation by women aged over 16 in the American labour force increased from 43\% to 61\% (Department of Labor 2005) and currently at $47 \%$ of the total work force. This increase in participation by women is closing the gap in participation across gender with women workers predicted to soon outnumber males. In Australia, the percentage of women aged between 25 and 34 in the Australian labour market has increased by three quarters in just one generation: from $41 \%$ to 71\% between 1970 and 1996 (Pusey 2003). Similarly, in Britain their participation has increased from $42 \%$ in 1980 to $47 \%$ in 2000. Being married now has less effect on women's participation in the workforce (McGovern, Smeaton \& Hill 2004). In 1960, fewer than 20\% of women with children under the age of 6 participated in paid work, yet in $200460 \%$ of these women and $75 \%$ of women with school-age children are 
participating in paid work, thereby being consistent with the general level of participation by women (Jacobsen, 2004). American women marry and have children later and fewer children, can access childcare, are less willing to interrupt education for marriage and more likely to have a career before marriage (Jacobsen 2004). Moreover, they have benefited from education to secure better paid work (Loutfi 2001). The increases in women's remuneration are held to be sourced in: (i) women's educational attainment, particularly in postgraduate education; (ii) work experience and lifetime hours worked; (iii) remuneration in some female dominated occupations and sectoral strips innovative demand and supply; and (iv) measures to combat blatant forms of gender pay and promotion discrimination (Jacobsen 2004). So across many western countries, women are participating more in the paid workforce than in earlier times. There are variations in this trend, with women's participation in paid employment being the norm in northern Europe and Scandinavia, whereas in Japan women are still expected to leave the workforce on marriage.

However, despite increased levels of participation and in work that is well remunerated, women have failed to secure benefits comparable to those males. Women are more likely to be employed part-time than their male counterparts leading to truncated and unsatisfactory career options (Tam 1997). The distribution of occupations in which women work tends to be quite narrow, often concentrated in particular occupational fields. $25 \%$ of American women report being employed in administrative support positions compared to only $5 \%$ of males. Only $2 \%$ of women against $20 \%$ of men report being employed in precision production work (Department of Labor, 2005). Similarly even in the relatively emancipated Nordic countries occupational segregation is relatively high (Anker 2001). Overall, women are also in receipt of lower levels of pay, although the gap is closing (Jacobsen 2004). It also seems that prospects for women remaining competent and enjoying successful careers will be dependent upon developing firm work identities through workplaces that support their career trajectories. Yet, this may not always be available to them.

The division between those who are highly skilled and highly paid and those who are lowly skilled and paid is not be distributed equally across national populations. African-Americans and Hispanic Americans disproportionately participate in low-wage work threatening the development of entrenched underclass perilously placed in changing working life requirements, and whose employment is often in precarious service work (Bernhardt 1999). Levels of education also distribute work options, with workforces being characterised by increasing levels of qualifications. In 1940, the majority of the US labour force (75\%) had less than a high school education (Employment Policy Foundation 2003). Yet, by 2002 those who had not completed a high school qualification were estimated that only $10 \%$ of the adult labour workforce. So, recipients of lower levels of education may struggle to secure effective and continuos employment.

Older workers are now a focus of attention in many Western countries. In the US, some have been required to work longer because of 
limited public pensions. However, the phenomenon of older workers is now predicted to be experienced more widely. Demographic changes in many countries means a requirement to work, remain competent far longer as well as growth in the provision of human services, including care for an ageing population (McNair, Flynn, Owen, Humphreys, \& Woodfield 2004). There is little evidence to suggest that older workers become less competent or capable, (Baltes \& Staudinger 1996), although there is decline in reaction times and physical strength, which can effect some kinds of work performance. Specific training and older workers' experience can compensate for some of these declines (Sigelman 1999). However, given the constant changing character of work, older workers may well need additional support to learn new work requirements as existing capacities become redundant. They may need to reaffirm their competence more often and at the cost of existing competence and identity. One view suggests that as older workers become an increasing component of workforces, employers will provide adequate support for their skill development. However, experience cautions supporting this optimistic view. Just as there is little evidence of a widespread employer sponsored childcare to support workforce participation by women with young children, there is no guarantee that employers will support older workers. Instead, the privileging of younger workers will be accentuated by their relative scarcity and will likely remain the focus of enterprise support, rather than older workers. Of course, this will be exercised by circumstances.

Overall, opportunities at work and impacts of recession likely impact most heavily on disadvantaged groups. These impacts are not wholly based on human capital (e.g. educational levels and experience), with factors associated with race, the age, ethnicity apparently shaping opportunities. So, changes in participation means a need to develop and maintain work skills will be for a longer and potentially discontinuous working life as individuals move in and out of the workforce and be need to focus on specific skill formations for workers at different stages of their working life.

\section{Changing work, changing workers}

Having identified changes to work, working life, work requirements and participation in work, it is important to understand and address the impacts upon individuals. Workers will experience these changes. Ultimately, the enactment of work is a human process and individuals will bring particular capacities, identities and sense of self to their work and in different ways and frequency throughout working life. Consequently, the changing requirements of work are engaged with, negotiated, and made sense of by individuals whose backgrounds and experiences are diverse and differentiated. The inevitability of change brings with it not only threats to existing competence, individuals' standing and confidence, but also by different degree opportunities for responding to those changes. In combination, the capacities, identity and agency of individuals to engage with and secure appropriate development, on the one hand, and the degree 
by which workplaces of other agencies, including vocational education and training institutions, on the other, support that development will shape the prospects for individuals to maintain their competence throughout an increasingly long, but turbulent working life. Yet, many vocational education systems are premised on standard curriculum provisions and industry-based requirements, that serve to deny the importance of the relevance and tailoring of these provisions to meet individuals' needs. So curriculum and instructional frameworks that are responsive to the diverse requirements of learners, rather than viewing them as having universal starting points, capacities, levels of readiness etc is likely to be required

\section{References}

Anker, R. (2001). Theories of occupational segregation by sex: An overview. In M. F. Loutfi (Ed.), Women, gender and work (pp. 129-155). Geneva: International Labour Organisation.

Bailey, T. (1993). Organizational Innovation in the Apparel Industry. Industrial Relations, 32(1), 30-48.

Baltes, P. B., \& Staudinger, U. M. (1996). Interactive minds in a life-span perspective. In P. B. Baltes \& U. M. Staudinger (Eds.), Interactive Minds:Life-span perspectives on the Social Foundations of Cognition (pp. 1-34). Cambridge: Cambridge University Press.

Barley, S. R., \& Orr, J. E. (1997). Introduction: The Neglected Workforce. In B. S. R \& O. J. E (Eds.), Between Craft and Science: Technical Work in US settings (pp. 1-19). Ithaca N Y: Cornell University Press.

Bartel, A. P., \& Lichtenberg, F. R. (1987). The comparative advantage of educated workers in implementing new technology. Review of Economics and Statistics, 65, 1-11.

Bernhardt, A. (1999). The future of low-wage jobs: Case Studies in the retail industry. Institute on Education and the Economy Working Paper, 10(March 1999).

Berryman, S. (1993). Learning for the workplace. Review of Research in Education, 19, 343-401.

Bertrand, O., \& Noyelle, T. (1988). Human resources and corporate strategy: Technological change in banks and insurance companies in five OECD countries. Paris: Organisation for Economic Cooperation and Development.

Billett, S., Smith, R \& Barker, M. (2005) Understanding work, learning and the remaking of cultural practices. Studies in Continuing Education 27 (3)

Billett, S., \& Somerville, M. (2004). Transformations at work: Identity and learning. Studies in Continuing Education, 26(2), 309-326.

Brunello, G., \& Medio, A. (2001). An explanation of International Differences in Education and Workplace Training. European Economic Review, 45(2), 307-322.

Carnevale, A. P. (1995). Enhancing skills in the new economy. In A. Howard (Ed.), The Changing Nature of Work. San Francisco: Jossey-Bass Publishers. 
Carnoy, M. (1999). The Great Work Dilemma. In J. Ahier \& G. Esland (Eds.), Education, Training and the Future of Work 1. London: Routledge.

Cook-Gumperez, J., \& Hanna, K. (1997). Some recent issues of professional literacy and practice. In G. Hull (Ed.), Changing work, Changing workers: Critical perspectives on language, literacy and skills (pp. 316-334). New York: State University of New York Press.

Danford, A. (1998). Teamworking and labour regulation in the autocomponents industry. vol 12, no 3 pp.409-431. Work, Employment \& Society, 12(3), 409-431.

Darrah, C. N. (1997). Complicating the concept of skill requirements: Scenes from a workplace. In G. Hull (Ed.), Changing work, Changing workers: Critical perspectives on language, literacy and skills (pp. 249-272). New York: CUNY Press.

Department of Labor. (2005). What jobs do American Women and men have? Retrieved 11th January 2005, 2005, from www.prb.org.

Employment Policy Foundation. (2003). An economic Primer to White Collar Reform. Washington: Employment Policy Foundation.

Handel, M. J. (2005). Trends in perceived Job Quality, 1989 to 1998. Work and Occupations, 32(1), 66-94.

Jacobsen, J. P. (2004, 3 March 2004). Women as labor Force Participants: Effects of Family and Organisational Structure. Paper presented at the Reaching the Top: Challenges and Opportunities for Women Leaders, Boston.

Korean Economic Planing Board (2005), Yearbook of Korean Statistics, retrieved $23^{\text {rd }}$ September 2005 from

Lipsig-Mumme, C. (1996, October 31-1 November 1996). Bridging the solitudes: Canadian perspectives on Research Partnerships in the New Work Order (Keynote Address). Paper presented at the ANTARAC Annual Conference, Melbourne.

Loutfi, M. F. (2001). Women, gender and work: An overview. In M. F. Loutfi (Ed.), Women, gender and work (pp. 3-20). Geneva: Internaltional Labour Organisation.

Martin, L. M. W., \& Scribner, S. (1991). Laboratory for cognitive studies of work: A case study of the intellectual implications of a new technology. Teachers College Record, 92(4), 582-602.

McBrier, D. B., \& Wilson, G. (2004). Going down? Race and downward occupational mobility for white collar workers in the 1990s. Work and Occupations, 31(3), 283-322.

McGovern P. (1996). Trust, discretion and responsibility: The division of technical labour. Work, Employment and Society, 10(1), 85-103.

McGovern P, Smeaton D, \& Hill S. (2004). Bad jobs in Britian. Work and Occupations, 31(2), 225-249.

McNair, S., Flynn, M., Owen, L., Humphreys, C. \& Woodfield, S. (2004). Changing work in later life: A study of job transitions: University of Surrey, Centre for Research into the Older Workforce. 
Noon, M., \& Blyton, P. (1997). The realities of work. Basingstoke, Hants: Macmillan.

Pusey, M. (2003). The Experience of Middle Australia. Cambridge, UK: Cambridge University Press.

Sigelman, C. K. (1999). Life-span Human Development (Vol. 3). Pacific Grove: Brooks/Cole Publishing Company.

Tam, M. (1997). Part-time employment: A bridge or a trap? Brookfield, USA: Aldershot.

United Kingdom Labour Force Survey (2005) retrieved $23^{\text {rd }}$ September 2005 from http://www.statistics.gov.uk/cci/nscl.

Van Horn, C. (1996). Economic change and the American worker: A background paper. In Twentieth Century Task Force on Retraining America's Workforce, No one left behind. New York: Twentieth Century Fund Press.

Zuboff, S. (1988). In the age of the smart machine: The future of work and power. New York: Basic Books. 